Journal of English Language Teaching

UNNES

http://journal.unnes.ac.id/sju/index.php/elt

\title{
Gendered perspective on online communication strategies: A case on English department students
}

\author{
Maulida Nur Aziza ${ }^{凶}$
}

English Department, Universitas Negeri Semarang, Indonesia

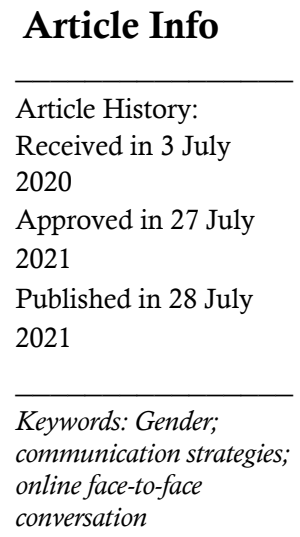

conversation

\begin{abstract}
This study aims to investigate whether gender influence on online communication strategies performed by the English Department. This study provides types of communication strategies, the frequency of communication strategies used, and the factors that influence students in differentiating communication strategies used by both male and female students. The researcher used qualitative approach. Online faceto-face conversation and interview were chosen as the data collection technique. For the research instruments that the researcher used were communication strategies sheet, interview, and audio and video recording. The participants of this study were the eight semester students of English Department. The data collected were analyzed used communication strategies taxonomies proposed by Celce-Murcia et al. (1995). The results of this study show that used variety of communication strategies. The most frequent communication strategy used both male and female students is fillers, hesitation devices, and gambits. It was proven by the percentage that was $50 \%$. The least used communication strategy by the students is circumlocution $(0,07 \%)$. Related to gender, female students almost show higher number of occurrences for all of the communication strategies than male students. This phenomenon happened due to some factors such as the female characteristics that is socially oriented, expressive and avoid making mistakes. Meanwhile, male students showed characteristics such as talk simpler, have a great willingness to manage anxiety and they seem to conceal their inability to others.
\end{abstract}




\section{INTRODUCTION}

Having effective communication skill in this industrial modern era is important. Research by Faradilla and Rukmini (2019) stated that to reach the goal of communication, English learner needs to have communication skill. She added that this is the tool in communication process which are used to remove barriers to reach effective communication. The fact that English is still considered as a foreign language in Indonesia makes the students have limited chance to apply and use it outside of school in their daily life. As a result, they rarely speak English as their language for communication. Hence, speaking skill is regarded as one of the most difficult aspects of language-learning (Leong \& Ahmadi., 2017). In line with this, many learners state that they have spent so many years studying English language, but they cannot speak it appropriately and understandably (Bueono et al., 2006). It seems that many Indonesian students may find it difficult when they have to speak in English. They put more effort or use some strategies to overcome their communication problem while speaking English. Those strategies called as communication strategies. Dornyei (1995) views communication strategies as the ways a person employs to cope with problems and difficulties in oral communication. Communication strategies can assist the students to solve their speaking problem and enhance their communicative competence. Hence, it is important for students to know about it.

A great number of studies concerning communication strategies have been carried out. Some researchers who had the same interest to this topic are Lai (2010), Kaivanpanah et al. (2012), Nasrullah (2017), Mahardika et al. (2014), Amin (2017), and Yusparizal et al. (2018). Those previous studies are similar to each other, but they had different categories to be observed. Most of them were focusing on investigating communication strategies used by male or female students, the percentage of it, and the reasons using communication strategies. They had the same interest, but they employed different research designs, research instruments, and numbers of participants, so they produced a different result. Concerning gender influence, there are still rooms for more investigation due to some inconsistencies in the findings of different studies.

Gender influence may give effect on communication strategies used by people. In line with that statement, Mahardika et al. (2014) mentioned that gender is believed as the factor affecting the process of communication. This statement is strengthened by the fact from the development of neuroscience reveals that men and women have differences in the structures and function in the brain (Rabinowicz et al., 2002). Achiron et al. (2001) stated that the different structures in male and female begin since in the womb. Furthermore, Frederikse et al. (1999) mentioned that brains are more asymmetric in men not in women. Regardless to those facts, it can be said that the different structure of their brain leads to the different ability to think, to communicate, or to solve problem between male and female. In this case, communication strategies used also influenced by gender.

Some experts had done doing a study related to gender and communication strategies. According to Zhao \& Intraprasert's research (2013), they found out that there is significant differences of individual communication strategies employment in relation to the students' gender. Female students used CS frequently than male students. This was consistent with the result study by Mahardika et al. (2014) in which stated that male students used 180 strategies while female students used 214 strategies. The contradicted result of the study related to this issue showed by Lai (2010). The findings from the interview showed that there was no significant differences between males and females in the use of CSs which was contributed to the learning environment. Another research conducted by Kaivanpanah et al. (2012), in which the results showed that there was no significant gender effect in the use of communication strategies except for strategies that were social in nature such as circumlocution, asking for clarification, omission, comprehension check, use of fillers, and over-explicitness. With respect to gender influence, there are still rooms for more investigation due to the differences in the findings of the previous studies. This study is trying to investigate the communication strategy used by English Department students based on gender. The different thing of this study compared to the others is the researcher is trying to investigate different communication strategies used affected by the students' gender and the communication partner's gender. In short, the researcher curious about whether the students use different communication strategies while communicating with the same gender and different gender or not.

Regarding the current situation in Indonesia and some countries in the world which got infected by the COVID-19, some countries implemented nationwide locked down. The government demanded all of the citizens to stay at home for several weeks or months for reducing and stopping the increasing numbers of infected patients by the coronavirus. Knowing how dangerous this virus is, the Indonesia 
government instructed all the citizens for supporting large scale social restriction. This instruction demanded some institutions to be closed and doing their activities through an online platform. Due to this situation, some outside activities were prohibited to be conducted, especially activity which cause a crowd. The researcher who initially wanted to conduct the real face-to-face conversation for collecting the data then changed the plan. An online platform that is WhatsApp video call was chosen as the application for collecting the data. This is because of the ease of use and all the students also have this application for their daily online chat.

Moreover, the different thing of this study compared to the previous studies is the researcher is trying to figure out different communication strategies performed by the students affected by the communication partner's gender. In short, the researcher curious about whether the students use different communication strategies while communicating with the same gender and different gender or not. Fishman (1983), Mahardika et al. (2014), Hancock and Rubin (2014), Amin (2017), Yusparizal et al. (2018), or Kaivanpanah et al. (2012), they focused on investigating gender influence on communication strategies. They tried to find out types of communication strategies performed based on gender. Meanwhile, for this study, the researcher differentiates it by using two interlocutors with different gender to be the communication partner of the students. This idea was inspired by Samar and Alibakhsi's research which seeking of gender influence on linguistic strategies, and they tabulated the data based on male and male, male and female, female and female, and female and male. What makes it different from that study is the researcher here investigating communication strategies. Besides, the research methodology used by the researcher were online face-to-face conversation and interview in which this is new for the related topic.

Building on the case above, the researcher was interested to conduct a research entitled Gendered Perspective on Online Communication Strategies: A Case on UNNES English Department Students. Then, the researcher formulates the research questions for this study as follows. The first research question is focusing on investigating types of communication strategies performed by English department students in their daily communication based on their gender and their communication partner's gender. The second research question is trying to figure out factors that influence the students in using communication strategies based on their gender and their communication partner's gender.

Reviewing the previous studies, there are some available communication strategies taxonomy that can be used. The first is taxonomy of communication strategies proposed by Tarone in 1977 (as cited in Dornyei \& Scott, 1997) which consisted of avoidance, paraphrase, conscious transfer, appeal for instance, and mime strategies. Later, Faerch \& Kasper (1983) postulated the taxonomy which comprised formal reduction, functional reduction, and achievement strategy (as cited in Dornyei \& Scott, 1997). Furthermore, other experts proposed other categories of communication strategies, they are Dornyei and Scott's taxonomy (1997). They categorized based on these main categories: interactional strategies, compensatory strategies, reduction strategies, focus-on form strategies, sociocultural strategies, and paralinguistic strategies. Afterward, for this study the researcher used communication strategies taxonomy proposed by Celce-Murcia et al. (1995) as the framework for analyzing the communication strategies performed by the students. The reason of this choice it is because the newest and completeness of the taxonomy. They suggested component of strategic communication as follow:

\section{AVOIDANCE OR REDUCTION STRATEGIES}

- Message replacement (e.g. It depend on your work. You will become better or worse (Fauziyah, 2013))

- Topic avoidance (e.g. I don't know (Palupi, 2008))

- Message abandonment (e.g. Clear and ... (faded in silence) (Palupi, 2008))

ACHIEVEMENT OR COMPENSATORY STRATEGIES

- Circumlocution (e.g. the thing you open bottles with for corkscrew)

- Approximation (e.g. fish for carp)

- All-purpose words (e.g. things, thing a majig)

- Non-linguistic means (mime, pointing, gestures, drawing pictures)

- Restructuring (e.g. The bus was very... there were a lot of people it)

- Word-coinage (e.g. vegetarianist)

- Literal translation from L1 (e.g. How many (Palupi, 2008))

- Foreignizing (e.g. to bor (Sukirlan, 2014))

- Code switching to L1 or L3 (e.g. Apa sih? (Sukirlan, 2014))

- Retrieval (e.g. bro... bron... bronze)

STALLING OR TIME-GAINING STRATEGIES

- Fillers, hesitation devices and gambits, (e.g. well, actually..., where was I...?) 


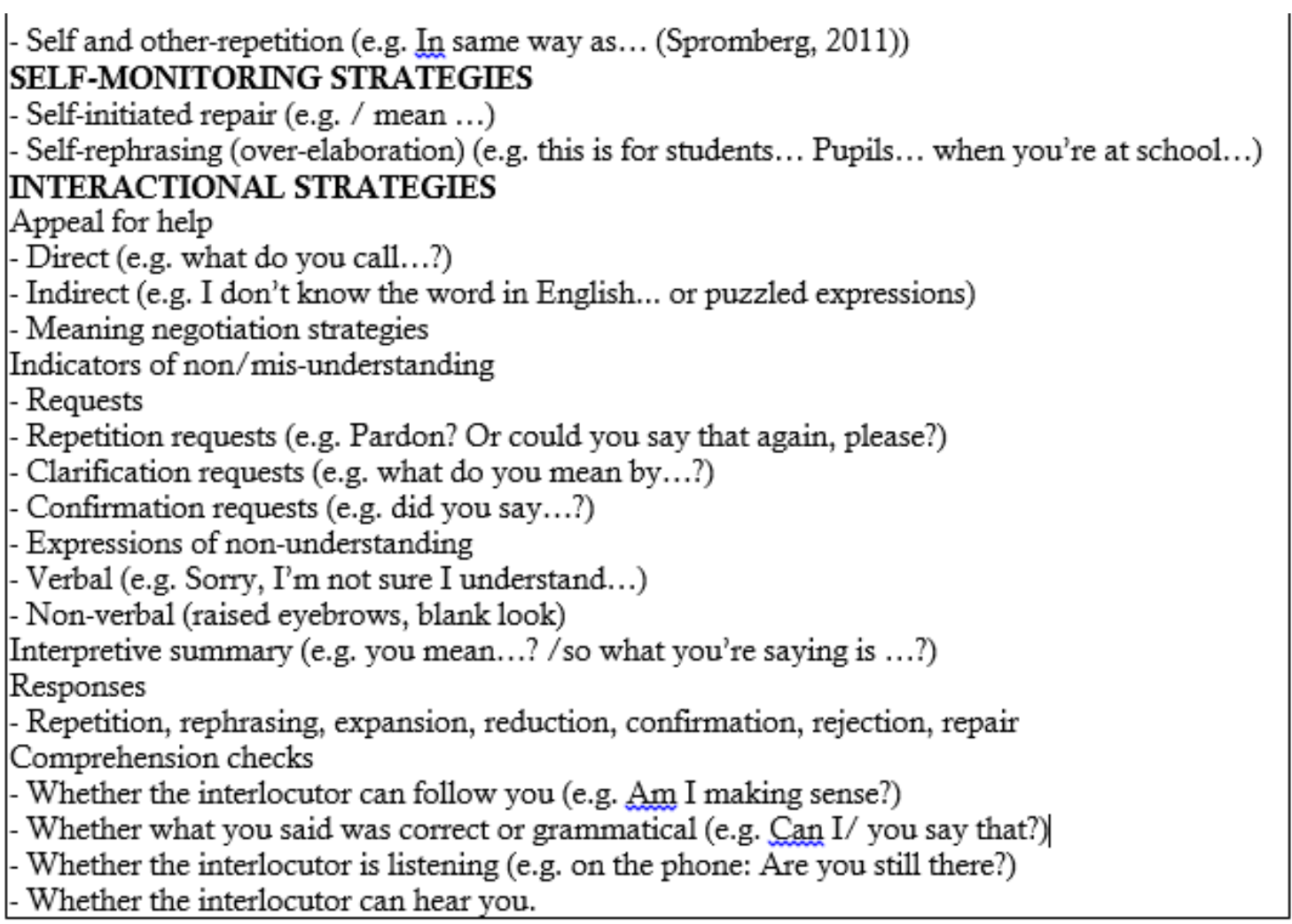

Figure 1. Communication Strategies Taxonomy by Celce-Murcia et al. (1995)

\section{METHODS}

This study used a qualitative approach. According to Polit et al. (1999, as cited in Purnomo, 2017), he stated that "qualitative research involves broadly stated questions about human experiences and realities, studied through people in their natural environments, generating rich, descriptive data that helps us to understand their experiences and attitude." This qualitative research focused on investigating gendered perspective on online communication strategies used by English department students. The conversation of this research was conducted naturally where the participants didn't recognize the focus objective of the research and it happened once for each person. There was no repetition so their answer was natural.

The subject of this study were the $8^{\text {th }}$ semester students of English Department. There were eight participants, i.e. four female students and four male students. This consideration is based on the statement from Creswell (1998) which recommends 5-25 subjects for phenomenological qualitative research. The researcher used purposive sampling when choosing the students as the participants in which the categories used are English department student, student of $8^{\text {th }}$ semester, and they are willing to join. Furthermore, the selected students had already taken basic courses of English learning in the previous semesters. Thus, the students were accustomed to speak English bravely. The reason of choosing eight semester students as the participants because they will graduate soon this semester, and hopefully, this research enriches their knowledge about communication strategy so they can speak English effectively and have a greater chance to have better job. This statement has been supported by Baker \& Westrup (2003) who said that learners who speak English very well can have greater chance for better education, finding good jobs, and getting promotion.

For collecting the data, the researcher employed some research instruments. They were communication strategies sheet, video recording, and interview. Communication strategies sheet was developed based on the taxonomy of communication strategies proposed by Celce-Murcia et al. (1995). The researcher printed out the communication strategies sheet for each student. The use of the communication strategies sheet itself in this study is as a guideline for the researcher to analyze and categorize the communication strategies used by the participants during the conversation. It helped 
the researcher to be more focus on collecting the data so there won't be any missing information that must be collected for analyzing the data. Furthermore, the researcher chose video recorder as another instrument used because it helped the researcher a lot in observing the communication strategies used by the students. It is because communication strategies not only consisted of verbal strategies in form of but also includes non-verbal strategies such as gestures or facial expression, so the researcher needs detail information about it and records it into a video. At last, interview is useful when there is a need to collect in-depth information in a systematic number of respondents. In this case, the interview needs to collect the participants' perception of using communication strategies to the different gender. Furthermore, by using the information from the interviews, it helped to strengthen the validity and reliability of this study.

For collecting the data, the researcher conducted an online face-to-face conversation and interview. All of the participants have a chance to communicate with the interlocutor both the same gender and opposite gender. The female interlocutor focused on discussing about university life while male interlocutor talked about studying abroad. The conversation was conducted through an online application called Whatsapp video call. The researcher chose this strategy due to the situation that happened in Indonesia that caused by COVID-19. The government demanded all of the citizens to stay at home. As a result, to overcome this situation, the researcher used an online face to face conversation. The data transcription of their conversation then was analyzed by using the taxonomy of communication strategies proposed by Celce-Murcia et al. (1995). Then, for the interview session, the researcher did the interview through Whatsapp call and recorded using audio recorder.

After conducting the online face to face conversation, the researcher collected the data and tried to figure out what communication strategies used by the participants. The classification of the collected data based on gender, for example, what communication strategies performed both males and males, females and males, males and females or females and females used. The result of analysis based on communication strategies sheet was crosschecked for two or three times to the video recorder transcription for avoiding any missed information that the researcher analyzed. Moreover, for the interview data analysis, the researcher transcribed the recording into words. Based on the transcription of the interview session, the researcher tried to interpret it to draw the conclusion. Interpreting was used to investigate the why the research subject used some communication strategies and their perception about gender of communication partner influence to their chosen communication strategies. At the last step is drawing the conclusion, based on the interpretation, the researcher can draw the final result of the interview.

\section{FINDINGS AND DISCUSSION}

\section{Communication strategies performed by the students}

The researcher had already collected the main data through an online face-to-face conversation with the participants. The data collected were in the form of video and audio recording. Those data were transcribed and then analyzed based on strategic competence from Celce-Murcia et al. (1995). Based on the data analysis, five sub-categories of communication strategies were employed by the students during their communication. Both male and female students used those five categories, but not all of the strategies were used by the students. There 16 communication strategies used among 19 strategies that proposed by Celce-Murcia et al. (1995). Those communication strategies that were used by the students during their conversations were topic avoidance, message abandonment, circumlocution, approximation, all-purpose words, non-linguistic means, restructuring, literal translation from L1, code-switching, retrieval, fillers, hesitation devices and gambits, self and other repetition, self-initiated repair, self-rephrasing, appeals for help, and meaning-negotiation strategies. Meanwhile, message replacement, word-coinage, and foreignizing were the strategies which never employed by the students during the conversation. Furthermore, the details analysis of the finding will be explained on the following paragraph with more explanation for the frequencies of each communication strategies, the description of the communication strategies used, and the interpretation of why the participants used those communication strategies related to gender.

Table 1. Table of recapitulation of communication strategies performed by the students

\begin{tabular}{ccccc}
\hline Type of Communication Strategies & \multicolumn{4}{c}{ Appearance } \\
\cline { 2 - 5 } & $\begin{array}{c}\text { Male to } \\
\text { male }\end{array}$ & $\begin{array}{c}\text { Male to } \\
\text { female }\end{array}$ & $\begin{array}{c}\text { Female to } \\
\text { female }\end{array}$ & $\begin{array}{c}\text { Female to } \\
\text { male }\end{array}$ \\
\hline $\begin{array}{c}\text { Message Replacement } \\
\text { Topic Avoidance }\end{array}$ & - & - & - & - \\
\end{tabular}




\begin{tabular}{|c|c|c|c|c|c|}
\hline $\begin{array}{c}\text { Avoidance or } \\
\text { Reduction } \\
\text { strategies }\end{array}$ & Message Abandonment & 4 & 11 & 11 & 11 \\
\hline Achievement or & Circumlocution & 1 & - & - & - \\
\hline Compensatory & Approximation & 4 & 15 & 4 & 3 \\
\hline \multirow[t]{8}{*}{ strategy } & All-purpose words & - & - & 1 & 1 \\
\hline & Non-linguistics mean & 4 & 15 & 11 & 5 \\
\hline & Restructuring & 3 & 8 & 2 & 10 \\
\hline & Word-coinage & - & - & - & - \\
\hline & $\begin{array}{l}\text { Literal translation from } \\
\text { L1 }\end{array}$ & 14 & 22 & 9 & 6 \\
\hline & Foreignizing & - & - & - & - \\
\hline & Code-switching & - & 6 & 11 & 19 \\
\hline & Retrieval & 2 & 1 & & \\
\hline \multirow[t]{2}{*}{$\begin{array}{l}\text { Stalling or Time- } \\
\text { gaining strategies }\end{array}$} & $\begin{array}{c}\text { Filler, hesitation devices } \\
\text { and gambits }\end{array}$ & 126 & 182 & 158 & 236 \\
\hline & Self and other repetition & 40 & 76 & 57 & 60 \\
\hline \multirow{2}{*}{$\begin{array}{l}\text { Self -monitoring } \\
\text { strategies }\end{array}$} & Self-initiated repair & 4 & 13 & 21 & 10 \\
\hline & $\begin{array}{l}\text { Self-rephrasing (over - } \\
\text { elaboration) }\end{array}$ & 10 & 18 & 6 & 10 \\
\hline \multirow{3}{*}{$\begin{array}{l}\text { Interactional } \\
\text { strategies }\end{array}$} & Appeals for help & 8 & 7 & 29 & 32 \\
\hline & $\begin{array}{c}\text { Meaning negotiation } \\
\text { strategies }\end{array}$ & 15 & 15 & 17 & 33 \\
\hline & Total & 236 & 393 & 338 & 437 \\
\hline
\end{tabular}

From the table of recapitulation above, both male and female students showed different number of occurrences. There was no significant gender effect on communication strategies used except for some strategies such as literal translation from L1, code-switching, fillers, hesitation devices and gambits, self-initiated repair, appeal for help, and meaning-negotiation strategies which showed significant differences. It can be deduced that excepts for those strategies mentioned above, the rest communication strategies showed similar numbers of usage. Here is the explanation for strategies that showed similar numbers of occurrences.

For topic avoidance and message abandonment strategies, both of them are the opposite of communicating. They are decisions not to communicate. If topic avoidance occurs when someone is trying to avoid some topics or concepts which they don't understand about and lack of vocabulary about it, message abandonment is a communication strategy used by the speaker when someone suddenly stops talking and leaving a message unfinished because of language difficulties. Here is the sample for topic avoidance "Yeah, I think. And then, the importance of education in college, I think [eee] I don't know, I don't know." For message abandonment, here is the sample "More be hard and ... [eee]". Students showed similar numbers of usage of these strategies. This finding revealed with Mahardika et al.'s study (2014) which found out that almost similar numbers used by male and female students for these strategies. The researcher speculates that they have the same characteristic that is avoiding talking about something they don't know about. Also, they may think that by using those strategies could enhance the effectiveness of communication. This statement echoed with Canale's study (1983) which argued that communication strategies can assist learners to enhance the effectiveness of communication. However, for this case, it was not suggested for the students to use these strategies a lot because it will make the interlocutors confused especially when leaving an unfinished message. This statement is supported by Mariani (1994) who stated that reduction strategy can affect the content of the communication goals.

Furthermore, for other strategies such as circumlocution (1), all-purpose words (1), and retrieval (3) which the most rarely used by the students, the researcher assumed that those strategies performed by the students unconsciously. One possible explanation for appearing of retrieval strategy by one male student it is because of the characteristic of the student itself. He might accustom to use this strategy while facing language difficulties, especially when speaking English. He retrieved the word until it complete and meaningful. Meanwhile, for the circumlocution strategy only appeared once. The researcher speculates that the students find it difficult when using this strategy. Circumlocution is a strategy in which the speaker overcome their speaking problem by describing or exemplifying the target object. They cannot remember the term or the word that they wanted to say, so how could possible they explain it using other words which leads the interlocutor to understand the 
message. This statement is supported by one of the participants who said in the interview "It is because to explain the words that I'm confused has already difficult things to do, how could be I can explain it using words. It makes me more confused." And for all-purpose word strategy which is used to explain a certain item using the general word as a compensatory, both male and female students rarely used it because they possibly have already known the words in English since they are English department students. Again, those three strategies showed no significant effect of gender in communication strategies used.

Moreover, approximation, self-rephrasing, and restructuring strategies are strategies that deal with the placement and use of words. Those strategies showed insignificant numbers of usage. These similarities both male and female students in performing these strategies perhaps because they prefer employing verbatim strategies. They are as English department students have better language proficiency compared to the other majors. Their understanding and stock of vocabularies in their mind might pursue them to explain something and coping their communication problems by arranging the words. That's why they used approximation, self-rephrasing, and restructuring as their communication strategies. The finding of approximation strategies was supported by Mahardika et al.'s research (2014) which revealed that there were slightly different numbers of occurrence both male and female students for this strategy. Besides, restructuring strategy in which showed lower rate appearances is echoed with Ugla's study (2013) which stated the finding of this strategy is a very low rate.

For non-linguistic means strategy, the occurrences of this strategy used by the students across gender are slightly different and showed a lower rate of occurrences. Male students performed it 19 times, while female students 16 times. These findings did not match with what they said in the interview session in which they said that to overcome their communication problems, they usually use gestures or explain it in other words. Online communication (video call) limit the use of gestures as compared to face to face conversation. Furthermore, this finding indicates that there is no gender affecting the use of this strategy. This fact echoed with their statement in the interview session which said that for overcoming their communication problems while speaking English, they would use gestures. One of the students said "Yes, it's always a problem. Sometimes I feel uncomfortable speaking in English, and the way I deal with it is by using body language or finding closest related words." Perhaps, this is an easier way for them to make the interlocutor understand their thought while they are confusing to explain using words. Yet, this strategy is not always successful to be applied because it has limitations and leads to misunderstanding if the interlocutor has a different perception. In addition, the researcher assumed that both male and female students are expressive. This is indifferent to Parkins' study (2012) who states that women are the more emotionally expressive gender in the realm of face-to-face communication. This statement indicates that when females have face-to-face communication, they will be emotionally expressive.

The last one is self-repetition. There was only one different number of occurrences of this strategy, 116 times for male students and 117 for female students. This strategy is the second-highest strategy used by the students during the conversation. There are slightly different numbers between female and male students. The researcher realized that there are significant different numbers of this strategy used by the male students to the interlocutor. They frequently used this strategy while talking to the opposite gender. Actually, the female students did the same, but the different numbers of occurrences are not significant. This phenomenon could happen because they felt more burden and nervous while talking to a different gender. This statement in line with one of the student's statements which said that he becomes more nervous when talking to someone of a different gender. Also, the similarities of this strategy used by them could be the cause of their eagerness not to make mistakes while speaking English. They gained time to think the correct utterances or words they want to say by repeating the words. This strategy also showed their intention to maintain communication.

To sum up, the similarities numbers of usage of those strategies mentioned above because the students both male and female want to enhance the effectiveness of communication, they prefer playing with the words, they are expressive, and they want to maintain the conversation by gaining time. For the following paragraphs, the researcher explains more about differences in communication strategies performed by the students. As mentioned above in the table, there are some categories that showed significant differences in the numbers of usage. Those strategies are literal translation from L1, code-switching, fillers, hesitation devices and gambits, self-initiated repair, appeal for help, and meaning-negotiation strategies.

Literal translation from L1 strategy was one of the favorite strategies used by the students. This was proven by the number of occurrences in which male students used it 36 times, while female 
students 15 times. Literal translation is translating words by words, the lexical item, idiom, compound words, or structure from L1 to L2. It means that the speaker directly translates the words without taking into consideration the grammatical of the sentence. Here is the sample, "... second is I live a far from my family and when. I'm feel so missing them, I just can look at by video call or calling my mom like that. Yeah, just that." The female student wanted to say that whenever she misses her family, she usually calls or video calls her mom. She didn't consider the grammatical aspect. As we can see, this strategy was more frequently used by male students rather than female students. Looking through the conversation of the participants, the male students spoke simpler and shorter sentences compared to the female students. This can be one possible explanation whereas the male students' characteristics in which say something to the point so that they uttered simply. This is in line with Mahardika et al's research which found out the male students have frequently used this strategy than female students.

For another strategy that showed differences numbers of usage is code-switching. Codeswitching is using L1 word with L1 pronunciation or a LT word with LT pronuniciation in L2. (Dornyei, 1995). In another words is including the use of the native language of words or utterance during the conversation in the target language. From this research, almost all of the students had ever used this strategy during their conversation with the interlocutors. One of the students mentioned that whenever he talked to the native speaker, he would like to change the language into the native language to make it clearer. The result of this strategy showed female students performed it more frequently which was 30 times while male students only 6 times. The researcher speculates that the female students' characteristic which is socially oriented influences them to perform any strategy as long as to maintain their conversation keep going. They don't want to leave ambiguity and see this strategy as an easier strategy for maintaining the conversation. This finding is supported by Fishman (1983) who stated that men use short responses to show a lack of interest while women would utilize more responses to demonstrate her participation and interest in the interaction.

Fillers, hesitation devices, and gambits is the most frequent strategy performed by the students. Whether male or female students used this strategy more frequently than other strategies. The result echoed with Mahardika et al's study which also found out that both male and female students use fillers most frequently. The use of fillers, gambits, and hesitation devices itself is used as gaining time for thinking what's they want to say. This is in line with Ikawati's finding (2011) which stated that students needed a little time to think about what to say next while they have oral communication.

Although they use this strategy frequently, but the numbers of usage are quite different. Female students performed it 394 times while male students 308 . The significant different numbers among them in using this strategy possibly because female students avoid silence during conversation and use this strategy as their way to show their effort to keep the conversation going. Yet, this cannot be the only consideration as the effect of gender on the use of this communication strategy, other variables such as individual characteristics, the background of knowledge, or enthusiasm in the topic discuss should be taken into account. Besides, the lower numbers of usage of the male students were probably caused by the fact that male students have confidence enough in conveying their thought while speaking. Like what Zhao and Intraprasert's study (2013) argued that male students had a greater willingness to manage anxiety while interacting in English to maintain the conversation than female students. That's why male students performed fewer numbers of usage as a consequence of their effort in managing their anxiety.

Regarding self-initiated repair strategies, again the female students employed this strategy more frequently than male students. Self-initiated repair is a strategy in which the speaker initiates to correct his words after he realized there is something wrong with his utterances. The findings of this resonate in Ugla's study (2013) that the research subject used a self-repair strategy extensively. This was to compensate for their low proficiency in the English language. The differences number of occurrences between female (31 times) and male students (17), the researcher speculates that female students are more aware of realizing their mistake compared to the male. This was probably somewhat strongly influenced by the innate characteristics of females. This could be a possible reason why females innately better at language learning (Oxford, Nyikos, and Ehrman, 1988). Consequently, they immediately aware of their mistakes and repaired their incorrect words.

For appeals for help strategy, Tarone (1977) gives a brief explanation about the appeal for assistance that the speaker asks for the correct term or structure. It means that the speaker asks another for help in order to help him with a certain term or item in the target language. The numbers of usage of this strategy is quite different for both female students and male students. On one hand, male students performed it only 15 times while female students used it 61 times. Another researcher who has the same result conducted by Hou (1998), he mentioned that the participants used more asking for 
help when they are performing the task. Different results showed by Mahardika et al's research (2014) which found out that male students more frequently used this strategy than female students. The researcher assumed that possible explanation of this strategy because male students didn't want to show their inability by asking with the interlocutors but they performed other strategies. In line with this, they argued that a similar gender between male students and the interviewer encourages the male students to ask the interviewer when finding difficulties.

Differed with the male students who handled their communication problems by performing other strategies, the female students who were social-oriented in communication tried to ask for help from the interlocutor to get the answer and help quickly. Female students typically rely heavily on verbally and socially mediated approaches in their interaction (Halpern, 1992 as cited in Vandergrift 1997). That's why they don't consider showing their difficulties to the interlocutors to get help from them. To sum up, male students are typically don't want to show their inability to others, while female students perceived this strategy as their way to cope with their communication problems quickly.

The last communication strategy which showed different numbers of usage is meaning negotiation strategies. Again, female students are dominating the numbers of usage of this strategy. Ugla et al. (2013) found out that the students used this strategy frequently, especially asking repetition requests. In line with that, this research found out that the use of meaning negotiation strategy was the second-highest communication strategy used by the female students, and the fourth-highest communication strategy used by male students. Regarding the gender perspective, the researcher argues that possible reason for explaining the frequent numbers of usage by female students because they do not want to leave ambiguity or uncertainty in the conversation. If we look back on types of meaning negotiation strategies that consist of indicators of non-misunderstanding, responses, and comprehension check, three of them help the speaker to clearer the ambiguity or checking the same understanding both the speaker and the interlocutor. They may think that this strategy also effective to deal with their communication problems. This statement is supported by the previous study from Yaman and Özcan (2015) which argued that negotiation for meaning strategies is effective oral communication strategies that help students overcome communication problems.

To sum up, among all of the communication strategies performed by the students, the female students are superior in employing the strategies. As we can see, the total number of CS used by female students is 775 while male students only 629. This was consistent with the results in Mori and Gobel's study (2006), in which females had more desire to make L2-speaker friends and greater interest in direct contact with English speaking people than their male counterparts. Other studies showed significant female superiority in the use of all language learning strategies (Ehrman and Oxford 1989; Ellis 1994). That statement strengthening the fact that female students employed more communication strategies.

\section{Factors that influence the students in using communication strategies}

To answer the research question number two, the researcher conducted semi-constructed interview. They were eight questions delivered to the students using Indonesia language because the researcher intended to dig up more information from the respondents. For the factors that influence the students in using communication strategies, the researcher had already collected the data. Based on the interview transcription, there are some factors which influence the students in using communication strategies, they are: closeness of the relationship, gender, age, social status, preferences and interest.

For closeness of the relationship, most of the students agreed that this factor influence their way of speaking style in communication. They said that whenever they talk to someone that is new or they don't know before, they will select their words. Like what female student's said "Partners in communication, right? I wouldn't mind whether they are boys or girls because I don't feel any different to have a conversation with either one. But it'll be matter if, for example, A and B both are my friends, but compared to A, I barely talk to B. So, that makes our communication quite plain."

Furthermore, gender is another factor which influence the students in communication. Some of the students mentioned that gender of the communication partner influences them in their conversation. They will treat and behave different while talking with someone with the opposite gender. They differentiate their words, their politeness and their gesture. One of the male student stated that "Yes. I think it is also about gender. The way I talk to the girls and boys are slightly different. I would be more polite when talking to the girls."

Besides closeness of the relationship and gender, social status and age also matter. This was proven by the male student's statement which said "Yes, indeed. I think it is due to the social status. The way I talk to my lecturers will be quite different from the way I talk to my fellow friends. I have to 
mind my language somehow." Besides, preferences and interest both the speaker and the interlocutor is influential for someone in communication. Some of the participants had the same argument about it and mentioned that this factor influence them to their communication style. One of them said "Perhaps the circumstance, relationship, and the range of the topic."

Another findings from the interview session is the students answer about the usual communication strategies that they used in their daily life. The researcher had already collected the data that show types of communication strategies performed by the students from the online face-toface conversation. On another side, the researcher asked the students about what type of communication strategies they usually used through this semi-structured interview in order to know how far their understanding about communication strategies. In fact, the result of the interview was slightly different from the result of the analysis of their communication strategies during the online face-to-face conversation. From the interview session, mostly mentioned that the students overcome their communication problems by using gestures, using similar words, description, asking for help, or switch their words into their mother tongue. However, the findings showed that there were 16 communication strategies employed by the students during the conversation. The following sentences provide the students' answers in the interview session.

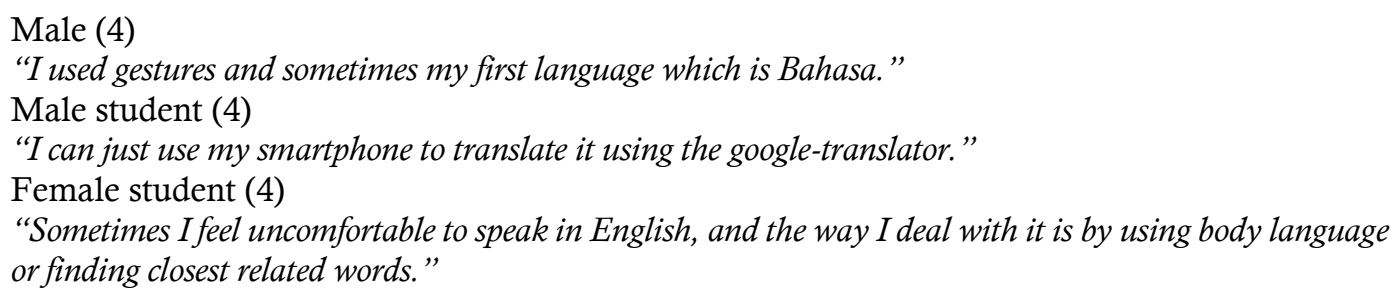

The first statement indicated that the student chose a code-switching strategy to overcome his communication problems. Meanwhile, the second statement provided a different strategy that he also prefered using a smartphone to help him while facing language difficulties. This strategy can be categorized as asking for help strategy. Furthermore, the female student's statement showed that she chose body language or gesture and finding closest related words. Finding the closest related words that the female student mentioned can be restructuring, self-rephrasing, circumlocution, or approximation strategy because those strategies focused on arranging words.

Based on the findings above, the researcher predicts that the difference between the students answer in the interview and their communication strategies used during conversation happened perhaps because they do not know about what the exact name of the communication strategy. Yet, actually, they have the concept of the strategy but they don't know any kind of other communication strategies, so they answered what they know. It can be concluded that the students employ more communication strategies rather than what they answered before. So, they need to know more about the types of communication strategies to help them improve their communication ability.

Besides, the explanation above can not be the one of the reasons for the differences that appeared in this strategy. Due to the use of Whatsapp video call, an online platform, as the instrument, the researcher speculates that other factors may influence it. Those extrinsic factors affect the different numbers itself. The factors can be the quality of the internet connection, the quality of the headset or speaker of the smartphone whether interlocutor or the students, the quality of the video recorder, and it can be the situation. What is meant by the situation here is whether are there any disturbance which affects the concentration of the students.

To sum up, there was no significant differences of CS used based on gender except for some strategies. This phenomenon happened caused by other factors such as topic discussion, the closeness of the relationship, topic, age, social status, preference and interest, internet connection, headset, video recorder, or the situation of the surrounding. For the future researcher, they need to try to conduct this study with different methods and numbers of participants. The researcher predicts that the result will be different if the study conducted face-to-face in real life.

\section{CONCLUSION}

There were no significant differences in communication strategies performed by the students based on gender except for some strategies. Those strategies are literal translation from L1, code-switching, fillers, hesitation devices and gambits, self-initiated repair, appeal for help, and meaning-negotiation strategies. They showed significant different numbers of occurrences. The researcher argues that the 
similarities number of occurrences happened because of some factors. Those factors include the students' eagerness to enhance the effectiveness of communication, the different of students' characteristics, they prefer playing with the words, they are expressive and they want to maintain the conversation by gaining time. Meanwhile, for the differences, it is influenced by some factors such as female students prefer avoiding silence in communication, females are socially oriented, males students speak simpler and to the point, innate ability of male and female, males students do not want to show their inability, and the students do not want to leave ambiguity. Besides, those factors, external factors also give a big impact on the numbers of occurrences. The external factors are the internet connection, the quality of headset/speaker of the smartphone, the quality of the video recorder, and the situation around the speakers or interlocutors.

Furthermore, based on the interview result, there are some factors that influence the participants in the conversation. Those factors are gender, the closeness of the relationship, topic, age, social status, preference, and interest. Interestingly, some students argued that they do not matter about the gender of the communication partner in affecting them while communicating. Based on the result of online face-to-face conversation, students who have that argument performed different result. Both male and female students performed frequent communication strategies towards different gender of the partner of communication. Any factors related to the gender difference which might influence them are the closeness of the relationship, topic, interest, characteristic of the communication partner, and the feeling that the speaker has toward the interlocutor. As a result, due to the different gender with the communication partner makes some students nervous, lack of confident, or limiting their body language. Hence, they performed frequent numbers of communication strategies used.

The researcher realizes that this research has limitation. Firstly, this research was conducted during the pandemic of COVID-19 viruses spreading around the world. Indonesian government demanded all of the citizen to stay at home. As a result, this study conducted through online platform. For the future researchers, they need to consider some matters such as the signal of the internet connection and the quality of the video and audio recorder while collecting the data through an online platform. Although, they are external factors, they have such a big impact on your data collection. The better of the audio and video recording, the better of the transcription and analysis as well. Communication strategies not only includes verbal words but also there are gestures, facial expression, or sound imitation which has to be analyzed. As a result, they need good quality of video and audio recording to get the best analysis of their studies.

Secondly, this research is limited to eight participants only. The researcher suggests that for the more concrete research, future researchers are better to use more participants and using different settings. For example, they can conduct a study that focused on investigating oral face-to-face conversation not online conversation. Furthermore, they can use different setting such as employing the real native speakers to have a face-to-face conversation with the participants. The more different methodologies used, the broader available resources related to this study. It is meant to gain concrete data and findings

\section{REFERENCES}

Achiron, R., Lipitz, S., \& Achiron, A. (2001). Sex related differences in the development of the human fetal corpus callosum: in utero ultrasonographic study. Prenatal diagnosis, 21(2), 116-120.

Amin, M.Y.M. (2017). Communication strategies and gender differences: A case study. International Journal of Humanities and Cultural Studies ISSN 2356-5926, 4(3), 226-236

Baker, J., \& Westrup, H. (2003). Essential Speaking Skills: A Handbook for English Language Teachers. London: Continuum.

Bueono, A., Madrid, D., \& McLaren, N. (2006). TEFL in Secondary Education. Granada: Editorial Universidad de Granada

Canale, M. (1983). From communicative competence to communicative language pedagogy. In Language and communication, eds. J. C. Richards and R. W. Schmidt, 2-27. Harlow: Longman

Celce-Murcia. M., Dörnyei Z., \& Thurrell S. (1995). A pedagogical framework for communicative competence: A Pedagogically motivated model with content specifications. Issues in Applied Linguistics, 6, 5-35.

Creswell, J. W. (1998). Qualitative inquiry and research design: Choosing among five traditions. Thousand Oaks, CA: Sage Publications. 
Dornyei, Z. (1995). On the teachability of communication strategies. TESOL Quarterly, 29(1), 55-85. Dornyei, Z. \& Scott, M. (1997). Communication strategies in a second language: definition and taxonomies. Language Learning, 47(1), 173-210.

Ehrman, M., \& Oxford, R. (1989). Effects of sex differences, career choice, and psychological type on adult language learning strategies, The Modern Language Journal, 73(1), 1-13.

Ellis, R. (1994). The study of second language acquisition. Oxford: OUP

Faradilla, A., \& Rukmini, D. (2019). The communicative competence components analysis in Using english through EIR. ELT Forum: Journal of English Language Teaching, 8(1), 78-85. https://doi.org/10.15294/elt.v8i1.27742

Faerch, F., \& Kasper, G. (1983). Strategies in Interlanguage Communication. Harlow: Longman

Fishman, P. (1983) 'Interaction: the work women do', in Barrie Thorne et al. (eds) Language, Gender and Society. Rowley, Mass.: Newbury House, pp. 89-101. First published 1978 in Social Problems 25(3), 97-406.

Frederikse, M. E., Lu, A., Alyward, E., Barta, P., \& Pearlson, G. (1999). Sex differences in the inferior parietal lobule. Cerebral Cortex, 9(8), 896-901

Hancock, A. B. \& Rubin, Benjamin. (2014). Influence of Communication Partner's Gender on Language. Journal of Language and Social Psychology. 34. 46-64.

Hou, S. S. (1998). Effect of tasks and genders oncommunication strategies. Journal of PLA University of Foreign Languages, 21(6), 18-23.

Ikawati, T. (2011). Communication Strategies Employed by the Students at SMA Negeri 8 Malang (unpublished master's thesis). Universitas Negeri Malang, Malang.

Kaivanpanah, S., Karami, H. \& Yamouty, P. (2012). Examining the effects of proficiency, gender, and task type on the use of communication strategies. Porta Linguarum, 17(1), 79-93.

Lai, H. (2010) Gender effect on the use of communication strategies, English language teaching, school of foreign languages, Lanzhou Jiao tong University, 3(4). http://ccsenet.org/elt

Leong, L., Ahmadi, S. M. (2017). An Analysis of Factors Influencing Learners' English Speaking Skill. IJREE 2017, 2 (1).

Mahardika, P., Sudirman, \& Suparman, U. (2014). The effect of gender on communication strategies used by ELT students. UNILA Journal of English Teaching, 3(2).

Mariani, L. (1994). Developing strategic competence: Towards autonomy in oral interaction. Perspectives, 20(1), 41-57.

Mori, S., \& Gobel, P. (2006). Gender, motivation, and attendance among university students. Proceedings of JALT 2004, Tokyo, 22 May 2004, 290-302.

Nasrullah. (2017). Communication strategies employed by the fourth semester students of English department of State University of Makasar. Jurnal Administrare: Jurnal Pemikiran Ilmiah dan Pendidikan Administrasi Perkantoran, 4(2), 83-96.

Oxford, R. L., Nyikos, M. \& Ehrman, M. (1988). Vive la difference? Reflections on sex differences in use of language learning strategies. Foreign Language Annals, 21(4), 321-329. shttp://dx.doi.org/10.1111/j.1944-9720.1988.tb01076.x.

Parkins, R. (2012). Gender and emotional expressiveness: An analysis of prosodic features in emotional expression. Griffith working paper in pragmatics and intercultural communication, 5(1), 46-54.

Purnomo, D. (2017). Communication Strategies Used by the Second Graders of Semesta Bilingual Elementary School. Final Project. English Department, Faculty of Languages and Arts, State University of Semarang.

Rabinowicz, T., Petetot, J. MacDonald-Comber, Gartside, P.S., Sheyn D., Sheyn, T., \& Gabrielle de Courten-Myers. (2002). Structure of the Cerebral Cortex in Men and Women. Journal of Neoropathology and Experimental Neurology, 61(1), 46-57

Tarone E. (1977). Conscious communication strategies in interlanguage: A progress report, in $\mathrm{H}$. D. Brown, C. Yorio \& R. Crymes (Eds.), On TESOL " 77: Teaching and Learning English as a Second Language.Washington, D.C.: TESOL.

Ugla, R. L., Nur, I. A., \& Abidin, M. J. Z. (2013). Study of Communication Strategies Used by Iraqi EFL Students. International Journal of Evaluation and Research in Education (IJERE), 2(1), 44-50.

Vandergrift, L. (1997). The comprehension strategies of second language French listeners: a descriptive study. Foreign Language Annals, 30(3), 387-409. 
Yaman, S.., \& Özcan, M. (2015). Oral communication strategies used by turkish students learning English as a foreign language. In: Pawlak M., Waniek-Klimczak E. (eds) Issues in Teaching, Learning and Testing Speaking in a Second Language: Second Language Learning and Teaching. Springer, Berlin, Heidelberg.

Yusparizal, Y., Irawati, E., \& Anugerahwati, M. (2018). Communication Strategies used by Elt Students Across Genders. Jurnal Pendidikan Humaniora, 6, 24-47.

Zhao, T., \& Intaraprasert, C. (2013). Use of communication strategies by tourism-oriented EFL learners in relation to gender and perceived language ability. English Language Teaching, 6(7), 46-59. https://doi.org/10.5539/elt.v6n7p46 